\title{
Short communication: Relationships between milk quality and acidification in the production of table Mozzarella without starters
}

\author{
M. Faccia, ${ }^{1}$ A. Trani, and A. Di Luccia \\ Dipartimento di Progettazione e Gestione dei Sistemi Agro-zootecnici e forestali Università degli Studi di Bari, Via Amendola 165/A, \\ 70126 Bari, Italy
}

\begin{abstract}
The effect of some quality parameters of the milk (refrigeration time, $\mathrm{pH}$, protein, and fat/protein ratio) on the extent of acidification in the production technology of table Mozzarella without starters was investigated. A screening phase carried out at the laboratory level demonstrated that variations of the milk characteristics require different levels of acidification to keep constant the quality of the cheese. The elaboration of the data collected throughout the successive experimentation on industrial scale allowed us to find a mathematical model to describe the relationships between the $\mathrm{pH}$ of the curd at stretching time and the milk characteristics, of which the protein concentration and the refrigeration time play the main roles.
\end{abstract}

Key words: Mozzarella, curd pH, milk acidification

The production technology of Mozzarella involves a phase of strong acidification of the milk or the curd, during which solubilization of micellar calcium takes place. This latter phenomenon is responsible for curd plasticization in hot water. This phase is performed throughout fermentation of the curd by lactic acid bacteria (biological procedure) or by direct adjunct of an acidifying agent to the milk (chemical procedure) before coagulation (Kindstedt, 2004). The biological procedure needs several hours to be completed, whereas the chemical process results in a ready-to-stretch curd, because it does not require the use of starter cultures. Even though the absence of lactic fermentation results in a flat flavor, the chemical procedure is widely used, because it results in lower production costs and better standardization of the characteristics of the cheese. However, this method presents a very critical step, which is the assessment of the level of milk acidification (amount of acid to be added) to obtain a suitable level of calcium solubilization. This is a crucial point, determining not only the stretching properties of the curd,

Received February 23, 2009.

Accepted May 5, 2009.

${ }^{1}$ Corresponding author: michele.faccia@agr.uniba.it but also the consistency of the finished product because of the influence of $\mathrm{pH}$ on water retention (McMahon et al., 2005). Consistency is a very important property for table Mozzarella, but unfortunately, a science-based method for the prediction of the level of preacidification is not available, and the problem is usually resolved by standardizing the cheese milk. When milk standardization is not performed (e.g., in small and medium-sized dairies), variations in milk composition cause changes in the amounts of acid to be added, which are commonly established by empirical procedures. A very popular method is the so-called stretching trial, which consists of stretching in hot water a small amount of curd previously prepared using a few liters of milk with a known amount of acid added. During stretching, the dairy operator evaluates the rate at which the curd elongates by gravity force and the appearance of the stretched curd, which has to be smooth and homogeneous. Then, the operator decides if the amount of acid requires adjustments. This procedure gives useful indications but needs very skilled workers able to perform the trial, evaluate the results, and make the suitable corrections. To implement a more simple and scientific procedure, a method based on measurement of $\mathrm{pH}$ has been proposed as an index for the prediction of stretchability properties of the curd. The method is based on the simple consideration that the lower the $\mathrm{pH}$, the higher the curd stretchability and retention of water into cheese. According to this approach, a fixed value of $\mathrm{pH}$ should exist for any levels of consistency of Mozzarella, but this is not always confirmed in practice, and the literature is sometimes conflicting as to the optimum $\mathrm{pH}$ value, for which some authors indicate only a range (Salvadori del Prato, 1993, 2001; Guinee et al., 2002). It is worth noting that, to date, the research performed on this (or related) subject has been conducted mainly on low-moisture Mozzarella for pizza made from single-batch or standardized milk and has not considered the quality of raw matter among the experimental variables (Keller et al., 1974; Metzger et al., 2000, 2001a,b; Sheehan and Guinee, 2004).

In our opinion, the prediction of the stretching properties of the curd requires a more complex approach. 


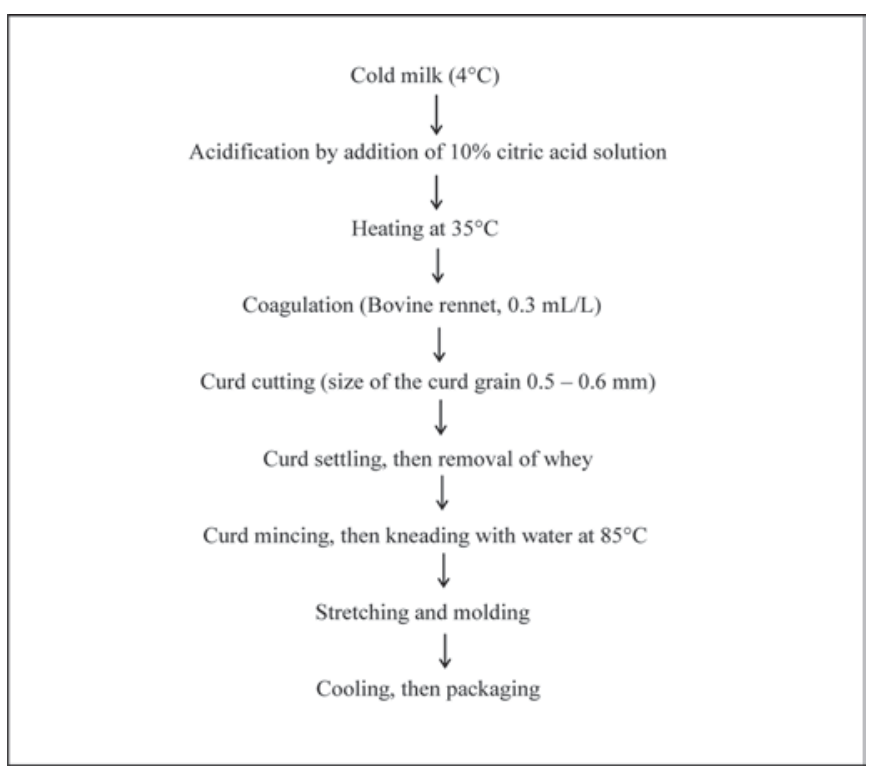

Figure 1. Flow diagram for the production of direct-acidified Mozzarella cheese.

The present communication, which is based on the results of a long collaboration between our research group and an industrial dairy, aims to contribute to a better understanding of the problem by studying the relationships between milk quality and level of acidification in the production process of high-moisture table Mozzarella cheese.

The investigation was performed on both a laboratory scale (screening phase) and an industrial scale. The screening phase consisted of 4 laboratory cheesemaking trials using milks with different chemical composition and keeping constant the value of curd $\mathrm{pH}$ at the stretching time. The trials were made in a small cheesemaking plant (30-L vats, indirectly steamheated) using 4 batches of fresh milk ( $4 \times 2$ replicates; Table 1). The cheeses were produced as reported in the flow diagram reported in Figure 1, and the addition of acid (citric acid) to milk was made in suitable amounts to reach a $\mathrm{pH}$ value of 5.8 in all trials. Experimentation on the industrial scale was carried out by monitoring the production process of a dairy specializing in the production of table Mozzarella (round cheeses weighing $150 \mathrm{~g}$ ) that does not perform standardization of the raw material and processes about 40,000 L of milk/d. The technological process used in the industry was the same as that adopted for the laboratory trials except for the amounts of citric acid added, which were established daily by the stretching trial mentioned above. The production process was monitored $2 \mathrm{~d}$ a week over about $1 \mathrm{yr}$, and 88 observations were collected; the corresponding data set is reported in Table
2. The monitored parameters were $\mathrm{pH}$, refrigeration time and composition (fat and total protein) of milk, $\mathrm{pH}$ of the curd at the stretching time (indicated as stretching $\mathrm{pH}$ ), amounts of citric acid added, moisture, and organoleptic characteristics of the cheese. The determination of $\mathrm{pH}$ was performed according to IDF procedures (IDF, 1989), whereas the concentration of fat and total protein in milk was determined by MilkoScan analysis (Milko Scan S50, Foss Electric, Hillerød, Denmark). The refrigeration time (RT) was calculated from milking to dairy processing, and 3 subgroups of milks were obtained: RT1 (milk processed within $1 \mathrm{~d}$ of milking), RT2 (within $2 \mathrm{~d}$ ), and RT3 (within $3 \mathrm{~d}$ ). The determination of moisture of the cheeses was carried out according to the IDF method (IDF 1970). The sensorial analysis was carried out by a panel of 6 experts (2 dairy managers, 2 dairy technicians, and 2 university researchers), who evaluated the sensory attributes of consistency and appearance. The analysis was based on the method of difference test: the panelists were asked to compare the samples under study with a reference sample (a standard high-moisture Mozzarella supplied by the same dairy industry involved in the study) and to a) indicate the differences of the consistency by using a scale from 0 (hard) to 5 (soft), where 3 was the consistency of the reference sample; b) describe the appearance of the surface (smooth or rough). Before evaluating, all samples were kept at room temperature for 20 min.

The data were processed by using JMP 4.0 Program (SAS Institute Inc., Cary, NC). The relation of stretching $\mathrm{pH}(\mathrm{Y}=$ dependent variable) to total protein, fat/ protein ratio, $\mathrm{pH}$, and refrigeration time of milk $(\mathrm{X}=$ regressors) was studied by multiple regression. To select a subset of effects for the regression model, the stepwise method was previously applied to the data set; it was performed in a backward direction using the values 0.250 and 0.100 as probability to enter and probability to leave the model, respectively.

The results of the screening phase demonstrated that the characteristics of the cheeses obtained by keeping the $\mathrm{pH}$ of the curd constant were very different (Table 3 ). The cheeses obtained from milk with a high protein content were harder and had less moisture than those made from low-protein milk, and this was also evident

Table 1. Chemical characteristics of the milks employed in the laboratory cheesemaking trials

\begin{tabular}{lccc}
\hline Trial & Protein $(\%)$ & Fat $(\%)$ & $\mathrm{pH}$ \\
\hline 1 & 3.13 & 3.58 & 6.71 \\
2 & 3.26 & 3.76 & 6.67 \\
3 & 3.35 & 3.91 & 6.69 \\
4 & 3.46 & 4.07 & 6.65 \\
\hline
\end{tabular}


Table 2. Data set of the "experimental" observations collected at industrial level ${ }^{1}$

\begin{tabular}{|c|c|c|c|c|c|}
\hline $\mathrm{RT}$ & Curd pH & $\mathrm{TP}$ & $\mathrm{CA}$ added & F:TP ratio & Milk pH \\
\hline 1 & 6 & 3.11 & 110 & 1.13 & 6.81 \\
\hline 1 & 5.99 & 3.09 & 110 & 1.11 & 6.79 \\
\hline 1 & 6.01 & 3.08 & 110 & 1.16 & 6.81 \\
\hline 1 & 5.97 & 3.12 & 110 & 1.12 & 6.78 \\
\hline 1 & 5.94 & 3.13 & 115 & 1.14 & 6.79 \\
\hline 1 & 6.04 & 3.11 & 110 & 1.12 & 6.8 \\
\hline 1 & 5.99 & 3.09 & 110 & 1.12 & 6.81 \\
\hline 1 & 5.89 & 3.21 & 115 & 1.13 & 6.78 \\
\hline 1 & 5.85 & 3.17 & 115 & 1.13 & 6.77 \\
\hline 1 & 5.89 & 3.19 & 115 & 1.15 & 6.79 \\
\hline 1 & 5.84 & 3.21 & 120 & 1.09 & 6.81 \\
\hline 1 & 5.89 & 3.2 & 115 & 1.15 & 6.8 \\
\hline 1 & 5.87 & 3.22 & 115 & 1.13 & 6.78 \\
\hline 1 & 5.82 & 3.22 & 120 & 1.13 & 6.76 \\
\hline 1 & 5.84 & 3.22 & 120 & 1.11 & 6.8 \\
\hline 1 & 5.83 & 3.25 & 125 & 1.12 & 6.75 \\
\hline 1 & 5.86 & 3.25 & 120 & 1.11 & 6.78 \\
\hline 1 & 5.77 & 3.26 & 125 & 1.15 & 6.74 \\
\hline 1 & 5.78 & 3.28 & 125 & 1.1 & 6.8 \\
\hline 1 & 5.82 & 3.28 & 125 & 1.09 & 6.75 \\
\hline 1 & 5.74 & 3.3 & 130 & 1.11 & 6.76 \\
\hline 1 & 5.7 & 3.35 & 130 & 1.21 & 6.71 \\
\hline 1 & 5.75 & 3.33 & 130 & 1.18 & 6.76 \\
\hline 1 & 5.73 & 3.3 & 130 & 1.14 & 6.72 \\
\hline 1 & 5.7 & 3.31 & 135 & 1.19 & 6.79 \\
\hline 1 & 5.72 & 3.32 & 135 & 1.15 & 6.74 \\
\hline 1 & 5.68 & 3.37 & 140 & 1.13 & 6.75 \\
\hline 1 & 5.6 & 3.41 & 145 & 1.18 & 6.7 \\
\hline 1 & 5.61 & 3.42 & 145 & 1.15 & 6.69 \\
\hline 1 & 5.64 & 3.4 & 145 & 1.21 & 6.73 \\
\hline 1 & 5.62 & 3.41 & 145 & 1.18 & 6.72 \\
\hline 1 & 5.56 & 3.46 & 150 & 1.14 & 6.67 \\
\hline 1 & 5.55 & 3.47 & 150 & 1.17 & 6.69 \\
\hline 1 & 5.58 & 3.45 & 150 & 1.15 & 6.68 \\
\hline 2 & 5.97 & 3.11 & 105 & 1.13 & 6.8 \\
\hline 2 & 5.98 & 3.09 & 105 & 1.11 & 6.77 \\
\hline 2 & 5.94 & 3.08 & 105 & 1.1 & 6.81 \\
\hline 2 & 5.99 & 3.12 & 105 & 1.12 & 6.78 \\
\hline 2 & 5.97 & 3.13 & 105 & 1.14 & 6.79 \\
\hline 2 & 5.89 & 3.11 & 105 & 1.12 & 6.78 \\
\hline 2 & 6.01 & 3.09 & 105 & 1.12 & 6.81 \\
\hline 2 & 5.98 & 3.21 & 105 & 1.13 & 6.78 \\
\hline 2 & 5.87 & 3.17 & 110 & 1.13 & 6.74 \\
\hline 2 & 5.94 & 3.19 & 110 & 1.15 & 6.79 \\
\hline 2 & 5.93 & 3.21 & 110 & 1.09 & 6.79 \\
\hline 2 & 5.95 & 3.2 & 110 & 1.15 & 6.77 \\
\hline 2 & 5.9 & 3.22 & 115 & 1.13 & 6.78 \\
\hline 2 & 5.92 & 3.22 & 115 & 1.13 & 6.76 \\
\hline 2 & 5.93 & 3.22 & 115 & 1.11 & 6.8 \\
\hline 2 & 5.91 & 3.25 & 120 & 1.12 & 6.75 \\
\hline 2 & 5.88 & 3.25 & 120 & 1.11 & 6.78 \\
\hline 2 & 5.91 & 3.26 & 120 & 1.1 & 6.74 \\
\hline 2 & 5.87 & 3.28 & 120 & 1.1 & 6.8 \\
\hline 2 & 5.83 & 3.28 & 125 & 1.09 & 6.75 \\
\hline 2 & 5.86 & 3.3 & 125 & 1.11 & 6.76 \\
\hline 2 & 5.8 & 3.35 & 130 & 1.2 & 6.71 \\
\hline 2 & 5.81 & 3.33 & 130 & 1.18 & 6.74 \\
\hline 2 & 5.91 & 3.3 & 125 & 1.14 & 6.72 \\
\hline 2 & 5.88 & 3.31 & 130 & 1.19 & 6.79 \\
\hline 2 & 5.85 & 3.32 & 130 & 1.15 & 6.74 \\
\hline 2 & 5.73 & 3.37 & 135 & 1.13 & 6.75 \\
\hline 2 & 5.82 & 3.41 & 135 & 1.18 & 6.7 \\
\hline 2 & 5.73 & 3.42 & 140 & 1.15 & 6.69 \\
\hline 2 & 5.7 & 3.4 & 140 & 1.21 & 6.71 \\
\hline \multirow[t]{2}{*}{2} & 5.75 & 3.41 & 135 & 1.18 & 6.72 \\
\hline & & & & & Contin \\
\hline
\end{tabular}

Table 2 (Continued). Data set of the "experimental" observations collected at industrial level $^{1}$

\begin{tabular}{lccccc}
\hline RT & Curd pH & TP & CA added & F:TP ratio & Milk pH \\
\hline 2 & 5.63 & 3.46 & 140 & 1.14 & 6.67 \\
2 & 5.61 & 3.47 & 145 & 1.17 & 6.65 \\
2 & 5.61 & 3.45 & 145 & 1.15 & 6.66 \\
3 & 5.97 & 3.11 & 100 & 1.09 & 6.72 \\
3 & 6.05 & 3.09 & 100 & 1.11 & 6.75 \\
3 & 6.02 & 3.08 & 100 & 1.08 & 6.73 \\
3 & 6.13 & 3.12 & 95 & 1.12 & 6.72 \\
3 & 6.07 & 3.21 & 105 & 1.09 & 6.71 \\
3 & 5.89 & 3.22 & 100 & 1.13 & 6.67 \\
3 & 6.05 & 3.22 & 95 & 1.13 & 6.71 \\
3 & 5.99 & 3.24 & 110 & 1.12 & 6.69 \\
3 & 6.01 & 3.25 & 110 & 1.11 & 6.68 \\
3 & 5.94 & 3.28 & 110 & 1.09 & 6.71 \\
3 & 5.95 & 3.3 & 115 & 1.14 & 6.7 \\
3 & 5.91 & 3.31 & 120 & 1.19 & 6.69 \\
3 & 5.81 & 3.32 & 130 & 1.15 & 6.71 \\
3 & 5.91 & 3.35 & 125 & 1.2 & 6.63 \\
3 & 5.8 & 3.42 & 135 & 1.15 & 6.61 \\
3 & 5.78 & 3.46 & 140 & 1.14 & 6.63 \\
3 & 5.72 & 3.47 & 140 & 1.17 & 6.64 \\
3 & 5.84 & 3.37 & 135 & 1.13 & 6.67 \\
3 & 5.78 & 3.41 & 140 & 1.18 & 6.64 \\
3 & 5.83 & 3.37 & 135 & 1.16 & 6.69 \\
\hline
\end{tabular}

${ }^{1} \mathrm{RT}=$ refrigeration time $(1,2$, or $3 \mathrm{~d}$ since milking $) ; \mathrm{TP}=$ total protein, $\mathrm{g} / 100 \mathrm{~mL} ; \mathrm{CA}=$ citric acid, $\mathrm{g} / 100 \mathrm{~L} ; \mathrm{F}=$ fat.

from the appearance of the rind, which proved to be smooth only in 2 cases. These results confirmed that an optimum $\mathrm{pH}$ value cannot be fixed absolutely, and that the prediction of the level of milk acidification requires a more complex approach. The statistical analysis of the data collected at the industrial level gave useful indications for the understanding of the relationship among milk quality and acidification; the results are summarized in Tables 4, 5, and 6 and in Figures 2 and 3 . The data set reported in Table 2 indicates that the quality of the raw material had wide variations, as did the stretching $\mathrm{pH}$, which ranged from a maximum of 6.13 to a minimum of 5.55. As shown in the stepwise fit table (Table 4), among the considered technological parameters, only total protein and refrigeration time entered the statistical model, whereas $\mathrm{pH}$ and fat/protein ratio were removed by backward selection. Based on these results, the model of Figure 2A was obtained, showing a good level of fitting $\left(\mathrm{R}^{2}=0.87\right)$ and highly significant value of Prob $>\mathrm{F}$. The parameter estimates (Table 5 ) indicated that $t$-test for the hypothesis zero for both regressors was $<0.0001$, and the following prediction equation for the model was found:

$$
\mathrm{Y}=8.91133+0.07017 \times \mathrm{RT}+(-0.976 \times \text { protein }) .
$$

Putting $\mathrm{Y}=$ amount of citric acid added $(\mathrm{g} / 100 \mathrm{~L}$ of milk, Table 2), the model was confirmed, and the prediction equation obtained was 
FACCIA ET AL.

Table 3. Characteristics of the cheeses obtained in the laboratory cheesemaking trials

\begin{tabular}{lccl}
\hline Trial & $\begin{array}{c}\text { Consistency (sensorial } \\
\text { analysis score) }\end{array}$ & Moisture $(\%)$ & Appearance of surface \\
\hline $1 \mathrm{a}$ & 4 & 65.3 & Smooth \\
$2 \mathrm{a}$ & 3 & 62.1 & Smooth \\
$3 \mathrm{a}$ & 2 & 56.0 & Slightly rough \\
$4 \mathrm{a}$ & 1 & 53.4 & Rough, irregular \\
$1 \mathrm{~b}$ & 3 & 66.2 & Smooth \\
$2 \mathrm{~b}$ & 3 & 60.3 & Smooth \\
$\mathrm{b}$ & 2 & 55.1 & Rough \\
$4 \mathrm{~b}$ & 1 & 52.0 & Rough, irregular \\
\hline
\end{tabular}

$$
\begin{gathered}
\mathrm{Y}=(-247.70921)+(-5.45793 \times \mathrm{RT}) \\
+116.237 \times \text { protein } .
\end{gathered}
$$

These results were expected, because both protein and RT are strongly related to the equilibrium of calcium in milk. Equation 1 indicates a positive correlation between stretching $\mathrm{pH}$ and $\mathrm{RT}$, whereas it was negative for protein content: the higher the protein, the lower the $\mathrm{pH}$ value; obviously, the correlations have the opposite sign in equation 2 . These results suggest that acidification of the milk has to be considered a type of titration of the protein content, which determines the level of colloidal calcium. In this view, considering the casein content of milk instead of total protein, the mathematical model should be improved.

The leverage plots reported in Figure 2B were useful to obtain further information about the effect of the single regressors. The distance from a point to the line of fit shows the actual residual error, whereas the distance from the point to the horizontal line of the mean shows what the residual error would be without the effect in the model. The plot for RT showed that the error increases with time, which could be explained by the fact that the storage of milk at low temperature tends to damage the casein micelle and, hence, to cause loss of colloidal calcium as ionic calcium in the serum phase. Variations in the extent of this phenomenon among the different milks processed should be a possible cause of the error. It is worth noting that such variations are deeply influenced by the activity of microflora, mainly psychrotrophic (Guinot-Thomas et al., 1995). This result suggested that the effect of protein should also change as RT changes. To ascertain this hypothesis, we tried fitting $\mathrm{Y}$ with protein by RT, considered an ordinal value. The corresponding results are shown in Figure 3. The 3 models obtained at each RT level continued to show strong significance, but, as expected, the error chance increased with time: $R^{2}$ changed from 0.97 (RT1) to 0.76 (RT3). This indicates that the variation in the response can be less efficiently absorbed by the model as milk storage proceeds.

In conclusion, this study demonstrated that the level of acidification of milk in the production of Mozzarella without starter cultures has to be established by taking into consideration a series of parameters, of which refrigeration time and chemical composition of the raw material play a primary role. The model reported should be a useful support for dairy operators to predict a suitable stretching $\mathrm{pH}$ and, as consequence, the amount of citric acid to be used.

\section{ACKNOWLEDGMENTS}

The authors thank the dairy company "Capurso Azienda Casearia SpA" of Gioia del Colle (Bari, Italy) and, in particular, Giovanni Ruppi for technical assistance.

\begin{tabular}{|c|c|c|c|c|c|c|c|c|c|}
\hline SSE & DFE & \multicolumn{2}{|c|}{ MSE } & $\mathrm{R}^{2}$ & \multicolumn{2}{|l|}{$\mathrm{R}^{2} \mathrm{Adj}$} & \multicolumn{2}{|c|}{$\mathrm{Cp}$} & $\mathrm{AIC}$ \\
\hline$\frac{0.1944318}{\text { Step }}$ & 85 & \multicolumn{2}{|c|}{0.002287} & $\frac{0.8712}{\mathrm{R}^{2}}$ & \multicolumn{2}{|l|}{0.8682} & \multicolumn{2}{|c|}{3.331296} & -532.121 \\
\hline 1 & Protein & Entered & 1.061 & 0.7030 & 112.77 & 2 & 484.20 & 0.0000 & -0.976335 \\
\hline 2 & Refrigeration time & Entered & 0.254 & 0.8712 & 3.3313 & 3 & 111.00 & 0.0000 & 0.070107 \\
\hline 3 & $\mathrm{pH}$ of milk & Removed & 0.005 & 0.8745 & 3.1186 & 4 & 2.24 & 0.1386 & - \\
\hline
\end{tabular}

Table 4. Stepwise fit response: $\mathrm{pH}$ of the curd; and stepwise regression control: current estimates and step history ${ }^{1}$

${ }^{1} \mathrm{SSE}=$ sum of squares error; DFE $=$ degrees of freedom error; MSE = mean square error; $\mathrm{Cp}=$ Mallow's Cp criterion; AIC $=$ Akaike information criterion; Seq SS $=$ sequential sum of squares; $\mathrm{p}=$ number of $\mathrm{x}$ variables +1 . 
a)

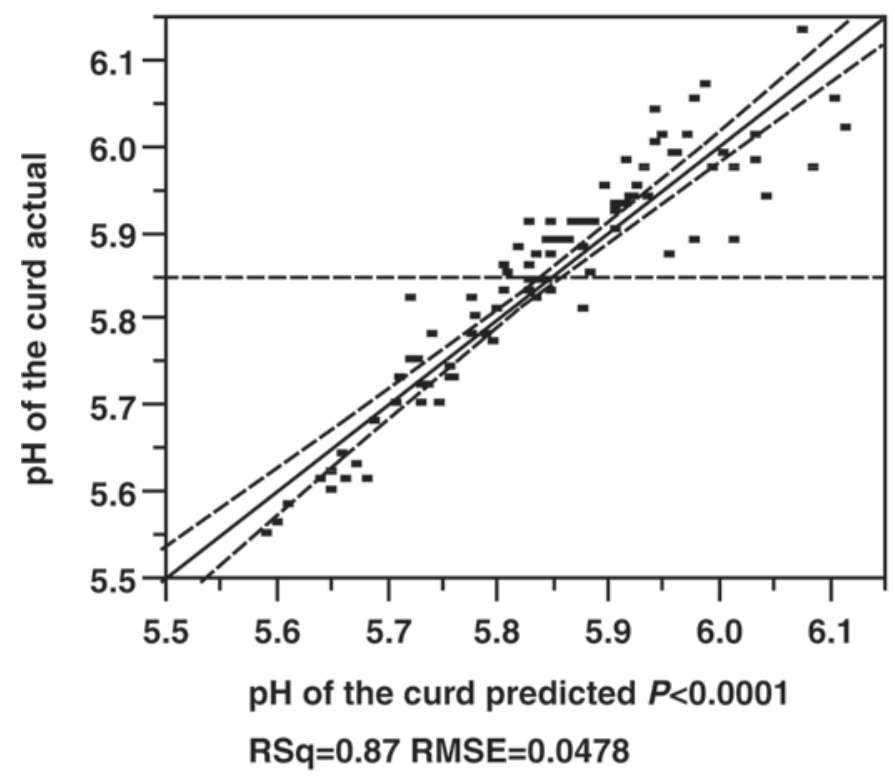

b)

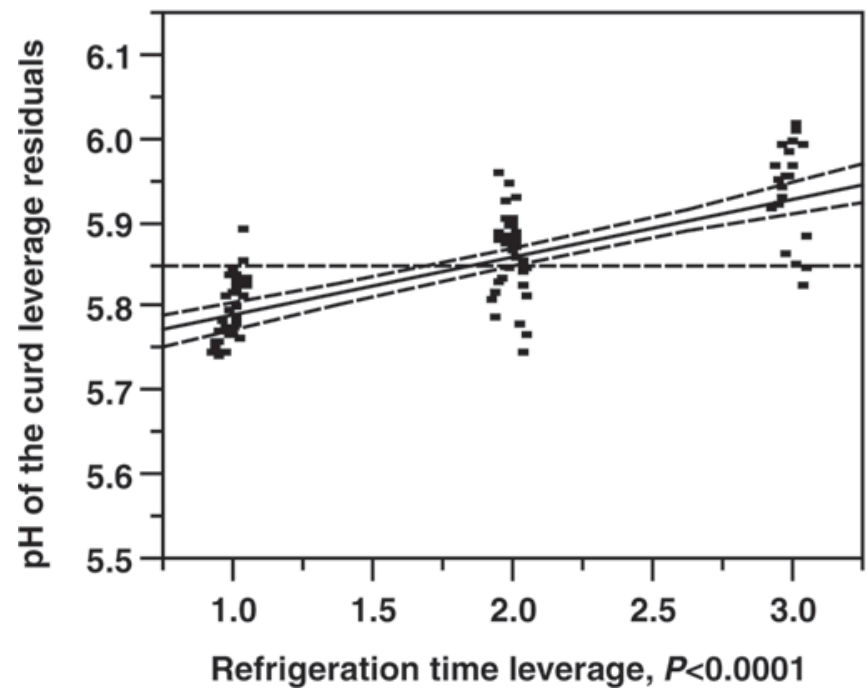

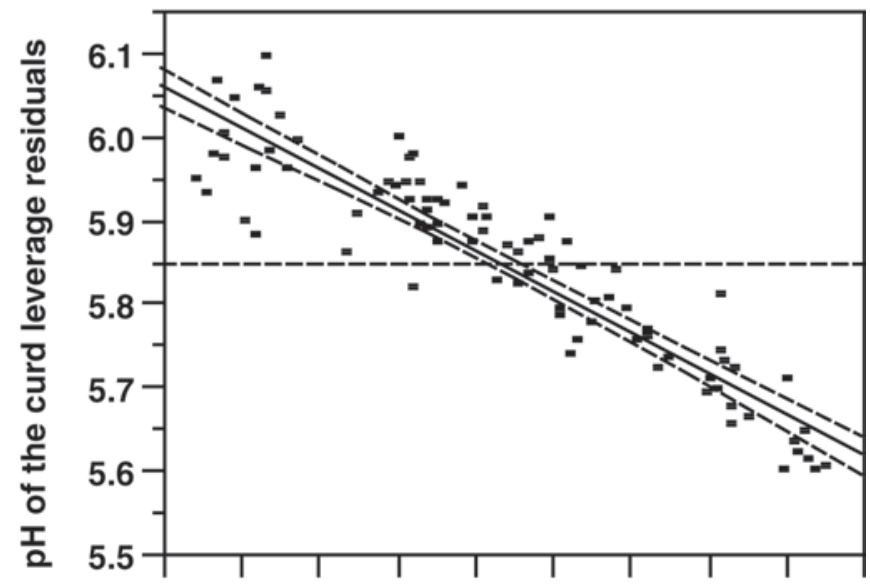

3.053 .103 .153 .203 .253 .303 .353 .403 .45 protein leverage, $P<0.0001$

Figure 2. a) Response "pH of the curd" whole model actual by predicted plot; b) leverage plots. RMSE = root mean square error.

Table 5. Response $\mathrm{pH}$ of the curd: ANOVA and parameter estimates

\begin{tabular}{|c|c|c|c|c|c|c|c|c|}
\hline Source & df & Sum of squares & Mean square & $F$ ratio & Estimate & $\mathrm{SE}$ & $t$ ratio & Prob $>|t|$ \\
\hline Model & 2 & 1.3149637 & 0.657482 & 287.4332 & & & & \\
\hline Error & 85 & 0.1944318 & 0.002287 & Prob $>F$ & & & & \\
\hline Corrected total & 87 & 1.5093955 & & $<0.0001$ & & & & \\
\hline Refrigeration time & & & & & 0.070107 & 0.006654 & 10.54 & $<0.0001$ \\
\hline Protein & & & & & -0.976335 & 0.04437 & -22.00 & $<0.0001$ \\
\hline
\end{tabular}




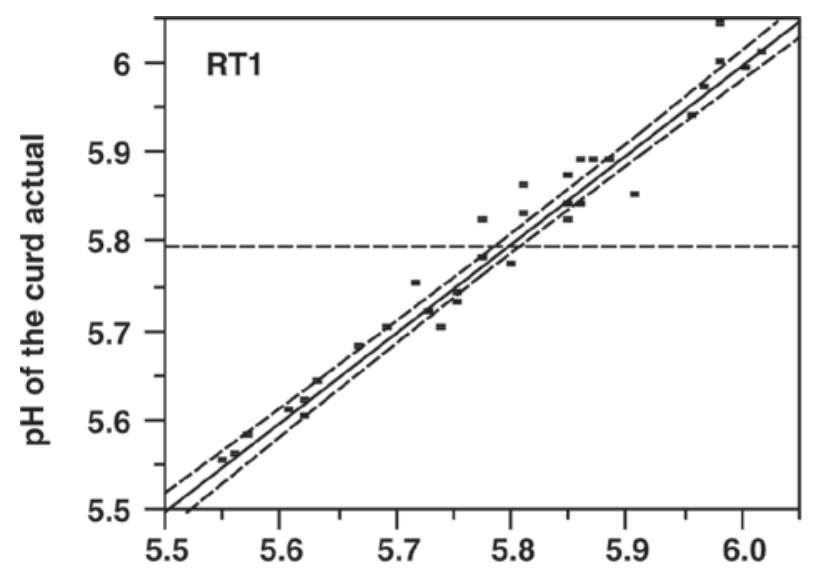

$\mathrm{pH}$ of the curd predicted $P<0.0001$

$\mathrm{RSq}=0.97 \mathrm{RMSE}=\mathbf{0 . 0 2 5 4}$

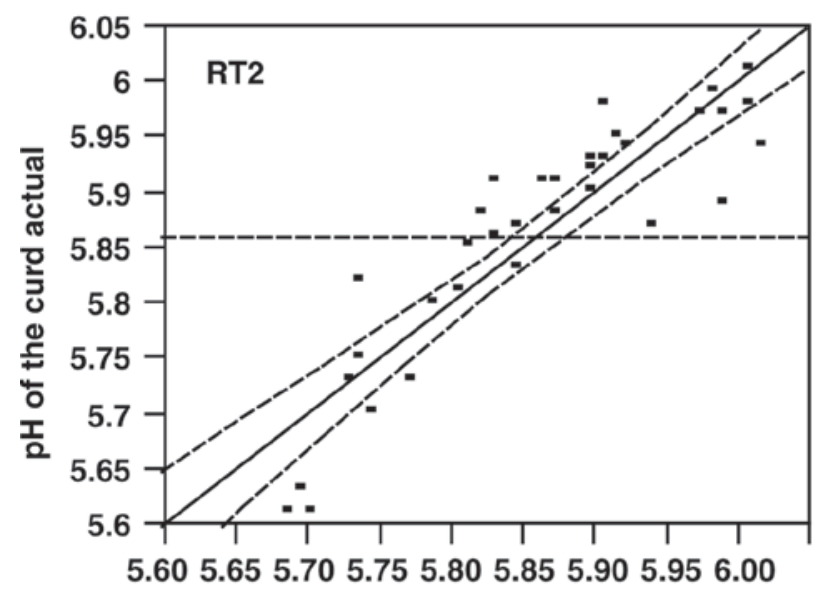

$\mathrm{pH}$ of the curd predicted $P<0.0001$

$\mathrm{RSq}=\mathbf{0 . 8 0} \mathrm{RMSE}=\mathbf{0 . 0 4 9 2}$

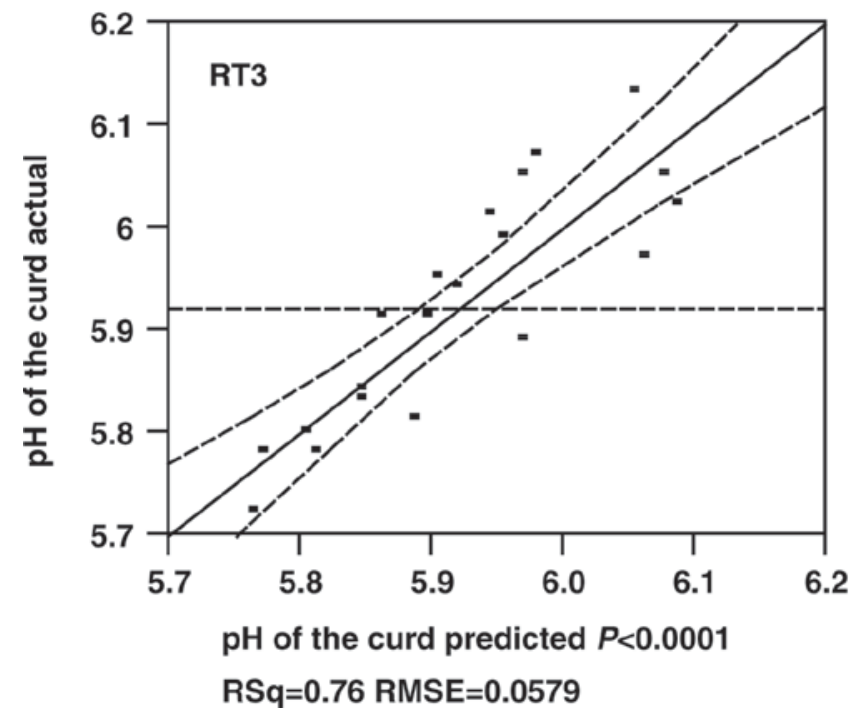

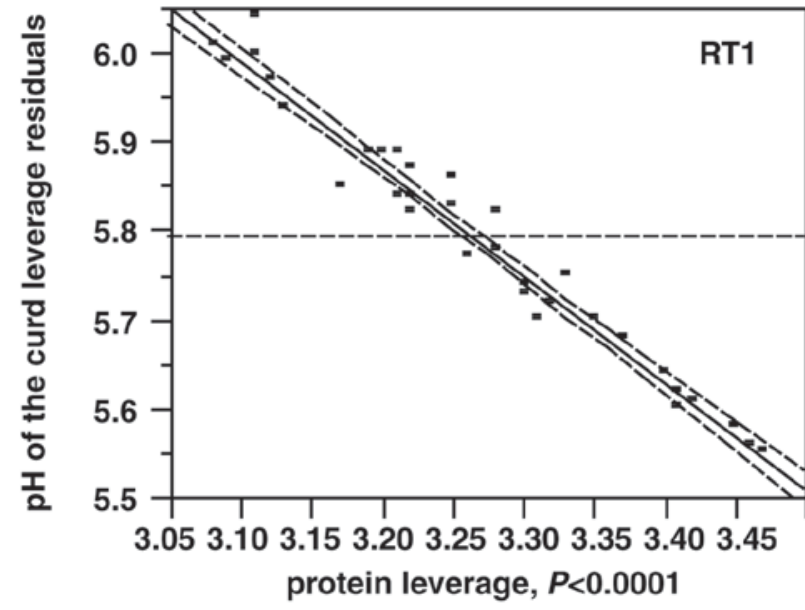
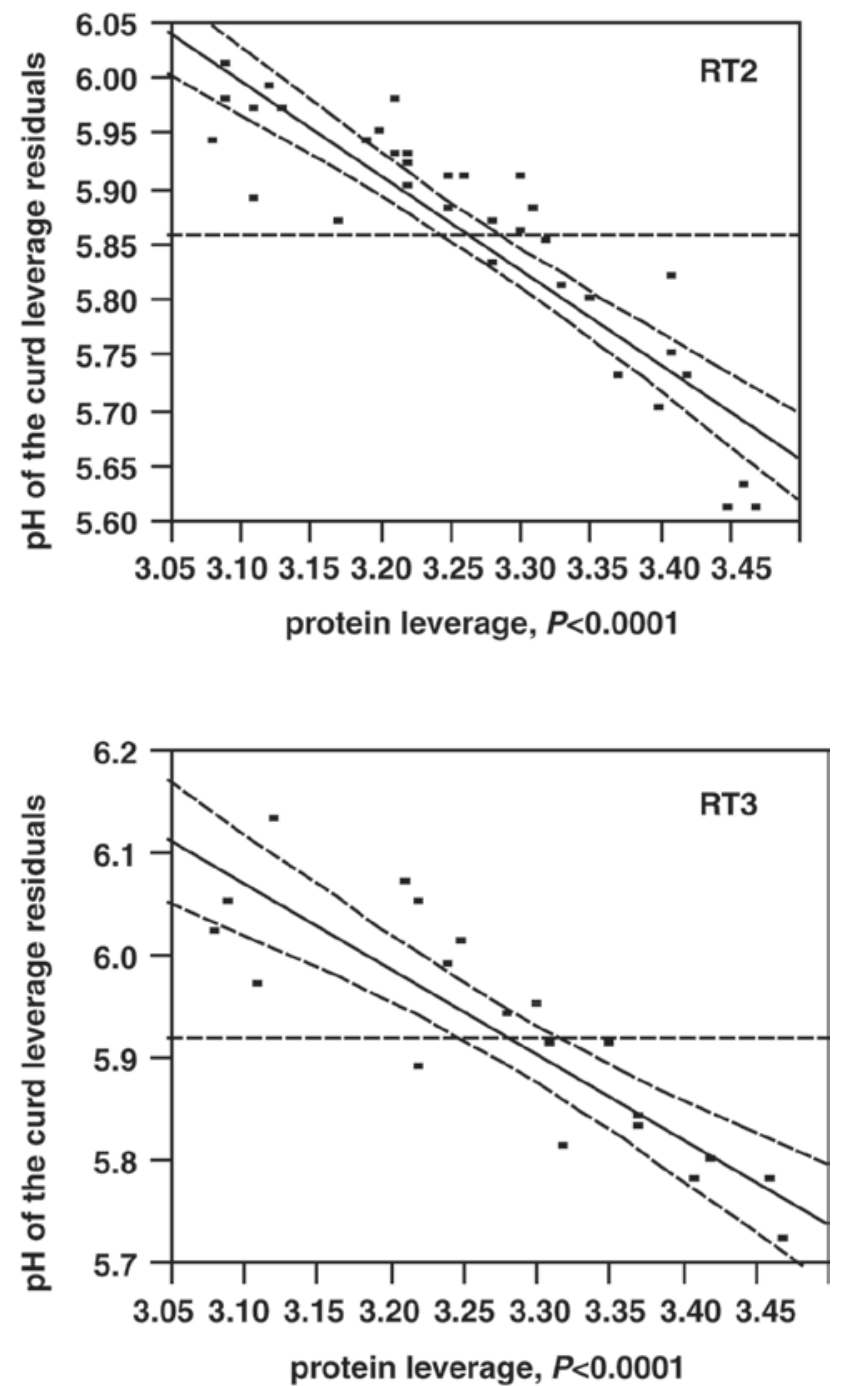

Figure 3. Models obtained by fitting $\mathrm{Y}$ (pH of the curd) with protein by refrigeration time (RT; RT1, RT2, and RT3 indicate milks processed within 1,2, and $3 \mathrm{~d}$ of milking, respectively). RMSE = root mean square error.

Journal of Dairy Science Vol. 92 No. 9, 2009 
Table 6. Response $\mathrm{pH}$ of the curd: ANOVA and parameter estimates (protein by refrigeration time, RT; RT1, RT2, and RT3 indicate milks processed within 1,2 , and $3 \mathrm{~d}$ of milking, respectively)

\begin{tabular}{|c|c|c|c|c|c|c|c|c|}
\hline Source & df & Sum of squares & Mean square & $F$ ratio & Estimate & $\mathrm{SE}$ & $t$ ratio & Prob $>|t|$ \\
\hline \multicolumn{9}{|l|}{ RT1 } \\
\hline Model & 1 & 0.63716095 & 0.637161 & 987.7510 & & & & \\
\hline Error & 32 & 0.02064199 & 0.000645 & Prob $>F$ & & & & \\
\hline Corrected total & 33 & 0.65780294 & & $<0.0001$ & & & & \\
\hline Intercept & & & & & 9.710087 & 0.12461 & 77.92 & $<0.0001$ \\
\hline Protein & & & & & -1.198964 & 0.038149 & -31.43 & $<0.0001$ \\
\hline \multicolumn{9}{|l|}{$\mathrm{RT} 2$} \\
\hline Model & 1 & 0.31843293 & 0.318433 & 131.7279 & & & & \\
\hline Error & 32 & 0.07735530 & 0.002417 & Prob $>F$ & & & & \\
\hline Corrected total & 33 & 0.39578824 & & $<0.0001$ & & & & \\
\hline Intercept & & & & & 8.6275 & 0.241225 & 35.77 & $<0.0001$ \\
\hline Protein & & & & & -0.847599 & 0.07385 & -11.48 & $<0.0001$ \\
\hline \multicolumn{9}{|l|}{ RT3 } \\
\hline Model & 1 & 0.18809048 & 0.188090 & 56.1608 & & & & \\
\hline Error & 18 & 0.06028452 & 0.003349 & Prob $>F$ & & & & \\
\hline Corrected total & 19 & 0.24837500 & & $<0.0001$ & & & & \\
\hline Intercept & & & & & 8.639086 & 0.36273 & 23.82 & $<0.0001$ \\
\hline Protein & & & & & -0.828228 & 0.110518 & -7.49 & $<0.0001$ \\
\hline
\end{tabular}

\section{REFERENCES}

Guinee, T. P., E. P. Feeney, M. A. E. Auty, and P. F. Fox. 2002. Effect of $\mathrm{pH}$ and calcium concentration on some textural and functional properties of Mozzarella cheese. J. Dairy Sci. 85:1655-1669.

Guinot-Thomas, P., M. Al Ammoury, and F. Laurent. 1995. Effects of storage conditions on the composition of raw milk. Int. Dairy J. 5:211-223.

IDF (International Dairy Federation). 1970. Determination of dry matter content in whey cheese. Standard 58, International Dairy Federation, Brussels, Belgium.

IDF (International Dairy Federation). 1989. Determination of $\mathrm{pH}$. Standard 115A, International Dairy Federation, Brussels, Belgium.

Keller, B., N. F. Olson, and T. Richardson. 1974. Mineral retention and rheological properties of mozzarella cheese made by direct acidification. J. Dairy Sci. 52:174-180.

Kindstedt, P. S. 2004. Mozzarella cheese: 40 years of scientific advancement. Int. J. Dairy Technol. 57:85-90.
McMahon, D. J., B. Paulson, and C. J. Oberg. 2005. Influence of calcium, $\mathrm{pH}$, and moisture on protein matrix structure and functionality in direct-acidified, nonfat Mozzarella cheese. J. Dairy Sci. 88:3754-3763.

Metzger, L. E., D. M. Barbano, and P. S. Kindstedt. 2000. Effect of milk preacidification on low fat Mozzarella cheese: I. Composition and yield. J. Dairy Sci. 83:648-658.

Metzger, L. E., D. M. Barbano, and P. S. Kindstedt. 2001a. Effect of milk preacidification on low fat Mozzarella cheese: II. Chemical and functional properties during storage. J. Dairy Sci. 84:13481356.

Metzger, L. E., D. M. Barbano, and P. S. Kindstedt. 2001b. Effect of milk preacidification on low fat Mozzarella cheese: III. Post-melt chewiness and whiteness. J. Dairy Sci. 84:1357-1366.

Salvadori del Prato, O. 1993. La mozzarella. Il Latte 5:594-604.

Salvadori del Prato, O. 2001. Trattato di Tecnologia Casearia. Edagricole, Bologna, Italy.

Sheehan, J. J., and T. P. Guinee. 2004. Effect of pH and calcium level on the biochemical, textural and functional properties of reducedfat Mozzarella cheese. Int. Dairy J. 14:161-172. 